\title{
Prevention of an Increase in Plasma Cortisol during Hypoglycemia Preserves Subsequent Counterregulatory Responses
}

\author{
S.N. Davis, C. Shavers, B. Davis, and F. Costa \\ Department of Medicine, Vanderbilt University School of Medicine, Nashville, Tennessee 37232
}

\begin{abstract}
The aim of this study was to determine whether preventing increases in plasma cortisol during antecedent hypoglycemia preserves autonomic nervous system counterregulatory responses during subsequent hypoglycemia. Experiments were carried out on 15 (8 male/7 female) healthy, overnightfasted subjects and 8 (4 male/4 female) age- and weightmatched patients with primary adrenocortical failure. $5 \mathrm{~d}$ before a study, patients had their usual glucocorticoid therapy replaced with a continuous subcutaneous infusion of cortisol programmed to produce normal daily circadian levels. Both groups underwent identical 2-d experiments. On day 1 , insulin was infused at a rate of $1.5 \mathrm{mU} / \mathrm{kg}$ per min, and 2-h clamped hypoglycemia $(53 \pm 2 \mathrm{mg} / \mathrm{dl})$ was obtained during the morning and afternoon. The next morning, subjects underwent an additional 2-h hypoglycemic $(53 \pm 2 \mathrm{mg} /$ dl) hyperinsulinemic clamp. In controls, day 2 steady state epinephrine, norepinephrine, pancreatic polypeptide, glucagon, growth hormone, and muscle sympathetic nerve activity were significantly blunted $(P<0.01)$ compared with day 1 hypoglycemia. In marked contrast, when increases of plasma cortisol were prevented in the patient group, day 2 neuroendocrine, muscle sympathetic nerve activity, hypoglycemic symptoms, and metabolic counterregulatory responses were equivalent with day 1 results. We conclude that $(a)$ prevention of increases of cortisol during antecedent hypoglycemia preserves many critical autonomic nervous system counterregulatory responses to subsequent hypoglycemia; (b) hypoglycemia-induced increases in plasma cortisol levels are a major mechanism responsible for causing subsequent hypoglycemic counterregulatory failure; and $(c)$ our results suggest that other mechanisms, apart from cortisol, do not play a major role in causing hypoglycemia-associated autonomic failure. (J. Clin. Invest. 1997. 100:429-438.) Key words: autonomic nervous system - hypoglycemia - catecholamines $\cdot$ cortisol $\cdot$ glucose clamp
\end{abstract}

\footnotetext{
Address correspondence to S.N. Davis, Division of Diabetes and Endocrinology, Vanderbilt University School of Medicine, Nashville, TN 37232-6303. Phone: 615-936-1653; FAX: 615-936-1667.

Received for publication 5 November 1996 and accepted in revised form 18 April 1997.
}

J. Clin. Invest.

(C) The American Society for Clinical Investigation, Inc.

0021-9738/97/07/0429/10 \$2.00

Volume 100, Number 2, July 1997, 429-438

\section{Introduction}

The annual incidence of severe hypoglycemia in insulindependent diabetic patients (IDDM) ${ }^{1}$ is increased threefold with intensive therapy (1). Previous studies have identified that intensively treated IDDM patients have acquired syndromes of autonomic nervous system (ANS) and neuroendocrine counterregulatory failure that predispose them to increased episodes of severe hypoglycemia $(2,3)$. Recent work has implicated antecedent episodes of hypoglycemia as the major cause of these acquired syndromes of counterregulatory failure (4-9). After the initial demonstration in normal volunteers by Heller and Cryer (5) that laboratory-induced antecedent hypoglycemia can result in blunted counterregulatory responses to subsequent hypoglycemia, several other studies have reported conceptually similar findings in normal individuals $(6,7,9)$, IDDM $(8,10)$, and patients with insulinoma (1113). These data have lead to the hypothesis that hypoglycemiaassociated autonomic failure in IDDM patients is caused by antecedent iatrogenic hypoglycemia (14).

Until recently, no data were available addressing the mechanisms responsible for antecedent hypoglycemia causing blunted subsequent counterregulatory responses. Boyle et al. have demonstrated adaptations that maintain brain glucose uptake at normal levels during repeated hypoglycemia, thereby reducing neuroendocrine counterregulatory responses (15). In addition, we have recently demonstrated in normal humans that physiologic increases in plasma cortisol, mimicking levels obtained during hypoglycemia, can produce similar ANS counterregulatory failure compared with antecedent episodes of hypoglycemia (16). Our previous results indicate that increases in plasma cortisol may be one of the major mechanisms responsible for antecedent hypoglycemia causing subsequent ANS counterregulatory failure. However, our previous study involved increasing plasma cortisol levels on a background of euglycemic hyperinsulinemia. Therefore, it is unknown whether additional, redundant mechanisms may operate during hypoglycemia that could also cause subsequent ANS counterregulatory failure. To definitively prove the role of plasma cortisol in the pathogenesis of hypoglycemia-associated autonomic failure, a model of antecedent hypoglycemia must be created that selectively prevents elevation of the hormone. To fulfill this need, a group of patients with primary adrenocortical failure on basal glucocorticoid and mineralocorticoid replacement therapy (i.e., fixed levels of cortisol) were investigated. The aim of the present study was, therefore, to determine whether preventing increases in plasma cortisol

1. Abbreviations used in this paper: ANS, autonomic nervous system; $\mathrm{CV}$, cell volume; EGP, endogenous glucose production; IDDM, insulin-dependent diabetic patients; MSNA, muscle sympathetic nerve activity; NEFA, nonesterified fatty acids; PNMT, phenylethanolamine- $N$-methyltransferase. 
during antecedent hypoglycemia will preserve ANS counterregulation during subsequent hypoglycemia.

\section{Methods}

\section{Subjects}

We studied 15 healthy volunteers ( 8 male/7 female), age $26 \pm 2 \mathrm{yr}$, body mass index $23.1 \pm 0.6 \mathrm{~kg} / \mathrm{m}^{2}$, glycosylated hemoglobin $\left(\mathrm{HBA}_{1 \mathrm{C}}\right)$ $4.7 \pm 0.1 \%$ (normal range 4 to $6.5 \%$ ) and 8 patients with documented primary adrenocortical failure ( 4 male/4 female) age $35 \pm 3 \mathrm{yr}$, body mass index $23.0 \pm 0.6 \mathrm{~kg} / \mathrm{m}^{2}, \mathrm{HBA}_{1 \mathrm{C}} 4.9 \pm 0.1 \%$. Volunteers were receiving no regular medication, and patients were taking only glucocorticoid and mineralocorticoid replacement therapy. Each subject had a normal blood count, plasma electrolytes, liver, and renal function. All gave written informed consent. Studies were approved by the Vanderbilt University Human Subjects Institutional Review Board. Subjects were asked to follow their usual weight-maintaining diet for $3 \mathrm{~d}$ before each study and were admitted to the Vanderbilt Clinical Research Center (CRC) at 1700 hours on the evening before an experiment. All subjects were studied after an overnight 10 -h fast.

\section{Experimental design}

$5 \mathrm{~d}$ before a study, patients' usual glucocorticoid therapy (hydrocortisone or prednisolone) was discontinued and replaced with a programmed continuous subcutaneous infusion of cortisol (total dose $12.5 \mathrm{mg} / \mathrm{d}$ ) so that normal daily circadian levels could be obtained. Mineralocorticoid replacement therapy ( $0.1 \mathrm{mg}$ fludrocortisone) was continued as usual in all patients.

Glucose clamp studies. Both groups attended for a single 2-d experiment. On the morning of the first day, after an overnight fast, two intravenous cannulae were inserted under $1 \%$ lidocaine local anesthesia. One cannula was placed in a retrograde fashion into a vein on the back of the hand. This hand was placed in a heated box $(55-60 \%)$ so that arterialized blood could be obtained (17). The other cannula was placed in the contralateral arm so that $20 \%$ glucose could be infused via a variable-rate volumetric infusion pump (I med, San Diego, CA).

\section{Antecedent hypoglycemia experiments}

On the morning of day 1 (Fig. 1), after the insertion of venous cannulae, a period of 90 min was allowed to elapse, followed by a 30-min basal control period and a 120-min hyperinsulinemic-hypoglycemic experimental period. At time zero, a primed continuous infusion of insulin (18) was administered at a rate of $1.5 \mathrm{mU} / \mathrm{kg}$ per min for $120 \mathrm{~min}$. Plasma glucose levels were measured every $5 \mathrm{~min}$ and a variable infusion of $20 \%$ dextrose was adjusted so that the rate of fall of plasma glucose and hypoglycemic plateaus of $53 \pm 1 \mathrm{mg} / \mathrm{dl}$ were equated in both groups (19). $\mathrm{KCl}$ (20 mmol/liter) was added to the glucose infusate in each study. After completion of the initial 2-h test period, each subject received a small snack ( $15 \mathrm{~g}$ carbohydrate in the form of fruit juice) and their plasma glucose was maintained at euglycemia for another $2 \mathrm{~h}$. At that point, insulin was restarted and a second hyperinsulinemic hypoglycemic clamp, identical to the morning, was performed. At completion of the second glucose clamp, subjects consumed a large meal, bedtime snack, and remained overnight in the CRC.

\section{Day 2 experiments}

Day 2 experiments involved standardized clamped hypoglycemia to assess the effects of day 1 hypoglycemia on subsequent hypoglycemic counterregulatory responses. After a 10 -h overnight fast, a third glucose clamp study was performed. The timing of the experiment was identical to the previous morning. To measure glucose kinetics, a primed, $(18 \mu \mathrm{Ci})$ constant infusion $(0.18 \mu \mathrm{Ci} / \mathrm{min})$ of $\left[3^{-3} \mathrm{H}\right]$ glucose was started at time $-120 \mathrm{~min}$ and continued throughout the 240 -min experiment. At time zero, a primed constant infusion of insulin at a rate of $1.5 \mathrm{mU} / \mathrm{kg}$ per min was started and the rate of fall of plasma glucose and hypoglycemic plateau $(\sim 53 \pm 1 \mathrm{mg} / \mathrm{dl})$ was controlled by a modification of the glucose clamp technique. A programmed continuous subcutaneous infusion of hydrocortisone was maintained during day 1 and day 2 study days. This ensured the usual 0600 hours spike of cortisol, but fixed basal levels of the hormone during each hypoglycemic clamp. Equal volumes of isotonic saline $(125 \mathrm{ml} / \mathrm{h})$ were administered to both groups.

The rates of glucose appearance $(\mathrm{Ra})$, endogenous glucose production (EGP), and glucose utilization (Rd) were calculated according to the methods of Wall et al. (20). EGP was calculated by determining the total rate of $\mathrm{Ra}$ (this comprises both endogenous glucose production and exogenous glucose infused to maintain the desired hypoglycemia) and subtracting from it the amount of glucose infused. It is now recognized that this approach is not fully quantitative, as underestimates of total $\mathrm{Ra}$ and $\mathrm{Rd}$ can be obtained. Using a highly purified tracer and taking measurements under steady state conditions (i.e., constant specific activity) in the presence of a low glucose flux

Experimental Protocol

Overnight Fasted Patients with Addisons Disease and Normal Subjects

Day 1

\begin{tabular}{|c|c|c|c|}
\hline \multirow[t]{2}{*}{ Time 0} & 0 & \multicolumn{2}{|c|}{6.0} \\
\hline & \multicolumn{2}{|l|}{ Saline } & Saline \\
\hline & Plasma Glucose $50 \mathrm{mg} / \mathrm{dl}$ & Plasma Glucose $90 \mathrm{mg} / \mathrm{dl}$ & Plasma Glucose $50 \mathrm{mg} / \mathrm{dl}$ \\
\hline & Insulin $1.5 \mathrm{mU} / \mathrm{kg} / \mathrm{min}$ & & Insulin $1.5 \mathrm{mU} / \mathrm{kg} / \mathrm{min}$ \\
\hline & ---- Microneurography .... & & \\
\hline
\end{tabular}

$+\quad$ Basal Cortisol Infusion in Addisons Group

Day 2

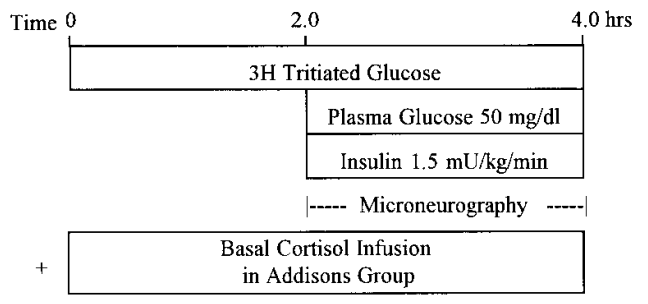

Figure 1. Schematic representation of experimental protocols used in this study. Results from day 2 morning experiments are compared with day 1 morning experiments to determine the effects of preventing increases of plasma cortisol on subsequent hypoglycemic counterregulatory responses. 
minimizes the major problems. Please note that isotopic determinations of glucose turnover were only quantified on day 2 , as it is unclear whether tracer infused on day 1 would be stored in glycogen and then released in unknown amounts during day 2.

\section{Direct measurement of muscle sympathetic nerve activity}

Microneurographic activity was recorded from the peroneal nerve at the level of the fibular head (21). The approximate location of this nerve was determined by transdermal electrical stimulation $(10-60 \mathrm{~V}$, $0.01 \mathrm{~ms}$ duration). This stimulation produced painless muscle contraction of the foot. After this, a reference tungsten electrode with a shaft diameter of $200 \mu \mathrm{m}$ was placed subcutaneously. A similar electrode, with an uninsulated tip (1-5 $\mu \mathrm{m})$ was inserted into the nerve and used for recording of muscle sympathetic nerve activity (MSNA). Placement of the recording electrode was guided by electrical stimulation (1-4 V, $0.01 \mathrm{~ms}$ duration). Electrical stimulation was performed with an S88 stimulator connected to an isolation unit (SIU8TB; Grass Instrument Co., Quincy, MA).

Recorded signals were fed to a preamplifier (1,000-fold amplification) and filtered using a band width between 700 and $2,000 \mathrm{~Hz}$. The filtered signal was rectified, amplified another 100 -fold, and integrated in a resistance-capacitance network using a time constant of $0.1 \mathrm{~s}$ (Nerve traffic analysis system 662C-3; University of Iowa Bioengineering, Iowa City, IA). The final signal was monitored using a storage oscilloscope (S111A; Tektronix Inc., Beaverton, OR) and recorded after fourfold amplification on a TA-2000 recorder (Gould Inc., Cleveland, $\mathrm{OH}$ ). A recording of muscle sympathetic nerve activity was considered adequate when $(a)$ electrical stimulation produced muscle twitches but not paresthesia, $(b)$ stretching of the tendons in the foot evoked proprioceptive afferent signals, whereas cutaneous stimulation by slight stroking of the skin did not, $(c)$ nerve activity increased during phase II of the Valsalva maneuver (hypotensive phase) and was suppressed during phase IV (blood pressure overshoot), and $(d)$ nerve activity increased in response to held expiration. Sympathetic nerve activity will be expressed as bursts per minute. Measurements of MSNA were made from the original tracings using a digitizer tablet (HIPAD; Houston Instruments, Austin, TX) coupled to Sigma Scan Software (Jandel Scientific, San Rafael, CA) in a micro computer. The effect of a given antecedent treatment on MSNA was expressed as change $(\Delta)$ from preceding control period.
Two types of sympathetic fibers (skin and muscle) can be identified from recordings of peripheral nerves. MSNA was recorded in the present studies because this has been demonstrated to reflect increased sympathetic activity during insulin-induced hypoglycemia (22), 2-deoxyglucose-induced neuroglycopenia (23) and hyperinsulinemic euglycemia in normal humans (24).

\section{Analytical methods}

The collection and processing of blood samples have been described elsewhere (25). Plasma glucose concentrations were measured in triplicate using the glucose oxidase method with a glucose analyzer (Beckman Instruments Inc., Fullerton, CA). Glucagon was measured according to a modification of the method of Morgan and Lazarow with an interassay cell volume (CV) of $15 \%$ (26). Insulin was measured as described previously (26) with an interassay CV of $11 \%$. Catecholamines were determined by high-pressure liquid chromatography (27) with an interassay CV of $17 \%$ for epinephrine and $14 \%$ for norepinephrine. We made two modifications to the procedure for catecholamine determination: $(a)$ we used a five- rather than a one-point standard calibration curve; and $(b)$ we spiked the initial and final samples of plasma with known amounts of epinephrine and norepinephrine so that accurate identification of the relevant respective catecholamine peaks could be made. Cortisol was assayed by using the Clinical Assays Gamma Coat radioimmunoassay kit with an interassay CV of $6 \%$. Growth hormone was determined by RIA (Linco Research Inc., St. Louis, MO) (28) with a CV of $8.6 \%$. Pancreatic polypeptide was measured by RIA using the method of Hagopian et al. (29) with an interassay $\mathrm{CV}$ of $8 \%$. ACTH was determined by RIA with a $\mathrm{CV}$ of $10 \%$ using the method of Nicholson et al. (30). Lactate, glycerol, alanine, and 3-hydroxybutyrate were measured in deproteinized whole blood using the method of Lloyd et al. (31). Nonesterified fatty acids (NEFA) were measured using the WAKO kit adopted for use on a centrifugal analyzer (Wako Chemicals, Dallas, TX).

Blood samples for glucose flux were taken every 10 min throughout the control period and every 15 min during the experimental period. Blood for hormones and intermediary metabolites were drawn twice during the control period and every 15 min during the experimental period. Cardiovascular parameters (pulse, systolic, diastolic, and mean arterial pressure) were measured noninvasively by a Dinamap (Critikon, Tampa, FL) every 10 min throughout each 300-min study. MSNA was measured continuously throughout each 300-min

Table I. Plasma Insulin, Glucose, and Cortisol Levels from Hyperinsulinemic (1.5 mU/kg per min) Hypoglycemic Clamp Studies from Morning and Afternoon of Day 1

\begin{tabular}{|c|c|c|c|c|c|c|c|c|c|c|}
\hline & \multicolumn{5}{|c|}{ Morning } & \multicolumn{5}{|c|}{ Afternoon } \\
\hline & $\begin{array}{l}\text { Control } \\
\text { period }\end{array}$ & 30 & 60 & 90 & $120(\min )$ & $\begin{array}{l}\text { Control } \\
\text { period }\end{array}$ & 30 & 60 & 90 & $120(\min )$ \\
\hline \multicolumn{11}{|l|}{ Plasma insulin $(\mu \mathrm{U} / \mathrm{ml})$} \\
\hline Normal controls & $6 \pm 1$ & $100 \pm 8^{*}$ & $91 \pm 7^{*}$ & $91 \pm 8^{*}$ & $91 \pm 9 *$ & $8 \pm 1$ & $89 \pm 2 *$ & $91 \pm 7 *$ & $90 \pm 6^{*}$ & $92 \pm 7 *$ \\
\hline $\begin{array}{l}\text { Primary adrenocortical } \\
\text { failure patients }\end{array}$ & $7 \pm 1$ & $88 \pm 7 *$ & $90 \pm 7 *$ & $89 \pm 6^{*}$ & $93 \pm 6^{*}$ & $9 \pm 1$ & $90 \pm 6^{*}$ & $89 \pm 5^{*}$ & $92 \pm 6^{*}$ & $91 \pm 6^{*}$ \\
\hline \multicolumn{11}{|l|}{ Plasma glucose $(\mathrm{mg} / \mathrm{dl})$} \\
\hline Normal controls & $92 \pm 2$ & $56 \pm 2^{\ddagger}$ & $56 \pm 2^{\ddagger}$ & $54 \pm 2^{\ddagger}$ & $52 \pm 2^{\ddagger}$ & $94 \pm 3$ & $70 \pm 2^{\ddagger}$ & $54 \pm 2^{\ddagger}$ & $54 \pm 2 \ddagger$ & $53 \pm 2^{\ddagger}$ \\
\hline $\begin{array}{l}\text { Primary adrenocortical } \\
\text { failure patients }\end{array}$ & $96 \pm 4$ & $65 \pm 2^{\ddagger}$ & $56 \pm 2^{\ddagger}$ & $54 \pm 2^{\ddagger}$ & $53 \pm 2^{\ddagger}$ & $97 \pm 5$ & $72 \pm 3^{\ddagger}$ & $55 \pm 1^{\ddagger}$ & $53 \pm 1^{\ddagger}$ & $53 \pm 1 *$ \\
\hline \multicolumn{11}{|l|}{ Plasma cortisol $(\mu \mathrm{g} / \mathrm{dl})$} \\
\hline Normal controls & $9 \pm 1$ & $11 \pm 2$ & $22 \pm 2^{*}$ & $25 \pm 2 *$ & $25 \pm 2 *$ & $12 \pm 2$ & $14 \pm 2$ & $20 \pm 2 *$ & $22 \pm 2 *$ & $23 \pm 2 *$ \\
\hline $\begin{array}{l}\text { Primary adrenocortical } \\
\text { failure patients }\end{array}$ & $7 \pm 2$ & $7 \pm 2$ & $7 \pm 2$ & $7 \pm 2$ & $5 \pm 2$ & $5 \pm 2$ & $5 \pm 2$ & $5 \pm 1$ & $5 \pm 2$ & $5 \pm 1$ \\
\hline
\end{tabular}

Values are mean \pm SEM. * Plasma insulin or cortisol concentrations are significantly increased $(P<0.05)$ compared with control period. ${ }^{*}$ Plasma glucose levels are significantly reduced $(P<0.05)$ compared with control period. 
study. Hypoglycemic symptoms were quantified during morning studies on days 1 and 2 using a previously validated semiquantitative questionnaire (32). Each subject was asked to rate his/her experience of the symptoms twice during the control period and every $15 \mathrm{~min}$ during the experimental period. Symptoms measured included tiredness, confusion, hunger, dizziness, difficulty thinking, blurred vision, sweats, tremors, agitation, hot/thirsty, and pounding heart. The ratings of the first six symptoms were summed to get a neuroglycopenic score while the ratings from the last five symptoms provide an autonomic symptom score.

\section{Materials}

HPLC-purified $\left(3^{-3} \mathrm{H}\right)$ glucose (New England Nuclear, Boston, MA) was used as the glucose tracer $(11.5 \mathrm{mCi} / \mathrm{mM})$. Human regular insulin was purchased from Eli Lilly and Co. (Indianapolis, IN). The insulin infusion solution was prepared with normal saline and contained $3 \%$ ( vol/vol) of the subject's own plasma. Hydrocortisone was purchased from Organon Teknika (West Orange, NJ).

\section{Statistical analysis}

Data are expressed as mean \pm SEM unless otherwise stated, and analyzed using standard, parametric, two-way ANOVA with a repeated measures design. This was coupled with a paired or unpaired Student's $t$ test to delineate at which time statistical significance was reached. $P<0.05$ indicated significant difference.

\section{Results}

Insulin, glucose, and cortisol levels from day 1 studies

Insulin values were at similar steady state levels by the final 45 min of morning and afternoon experiments in each group (Table I). Plasma glucose levels (Table I) were also stable and equivalent $(53 \pm 1 \mathrm{mg} / \mathrm{dl})$ during the final $45 \mathrm{~min}$ of morning and afternoon experiments. Plasma cortisol remained at basal levels (Table I) during patient studies but increased to $25 \pm 2$ and $23 \pm 3 \mathrm{~g} / \mathrm{dl}(n=5)$ during morning and afternoon control studies, respectively.

\section{Day 2 insulin, glucose, and neuroendocrine levels}

Insulin levels were equivalent $(92 \pm 10$ vs. $91 \pm 7 \mathrm{U} / \mathrm{ml})$ in patients and controls respectively (Fig. 2). Plasma glucose (Fig. 2) fell at an equivalent rate $(1.0 \pm 0.1 \mathrm{mg} / \mathrm{min})$ in all studies and reached a similar hypoglycemic plateau of $53 \pm 1 \mathrm{mg} / \mathrm{dl}$. The coefficient of variation of plasma glucose levels during the final $45 \mathrm{~min}$ of each protocol was $1.8 \%$.

Despite equivalent hypoglycemia and insulinemia, neuroendocrine responses on day 2 (Table II) were significantly blunted in controls but preserved compared with day 1 in patients. Day 2 steady state epinephrine values (i.e., last $45 \mathrm{~min}$ ) in controls (Fig. 3) were reduced compared with day 1 (404 \pm 56 vs. $786 \pm 101 \mathrm{pg} / \mathrm{ml}, P<0.01)$. In contrast, in the patient group, there was no reduction of day 2 relative to day 1 epinephrine values $(134 \pm 27$ vs. $156 \pm 28 \mathrm{pg} / \mathrm{ml})$. Incremental elevations in day 2 norepinephrine levels (Fig. 3) were significantly blunted compared with day 1 in controls $(+105 \pm 20$ vs. $+151 \pm 15 \mathrm{pg} / \mathrm{ml}, P<0.05)$, but were unchanged in the patient group $(+300 \pm 79$ vs. $+283 \pm 64 \mathrm{pg} / \mathrm{ml})$. Day 2 glucagon values

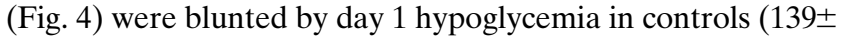
18 vs. $200 \pm 31 \mathrm{pg} / \mathrm{ml}, P<0.01)$, but were unaffected in the patient group $(120 \pm 22$ vs. $126 \pm 26 \mathrm{pg} / \mathrm{ml})$. Day 2 cortisol values (Fig. 4) were blunted after day 1 hypoglycemia in controls $(17 \pm 1$ vs. $25 \pm 2, P<0.01)$. Cortisol levels were controlled in patients at appropriate circadian levels $(5 \pm 1 \mathrm{~g} / \mathrm{dl})$.

Day 2 growth hormone values (Fig. 5) in controls were also

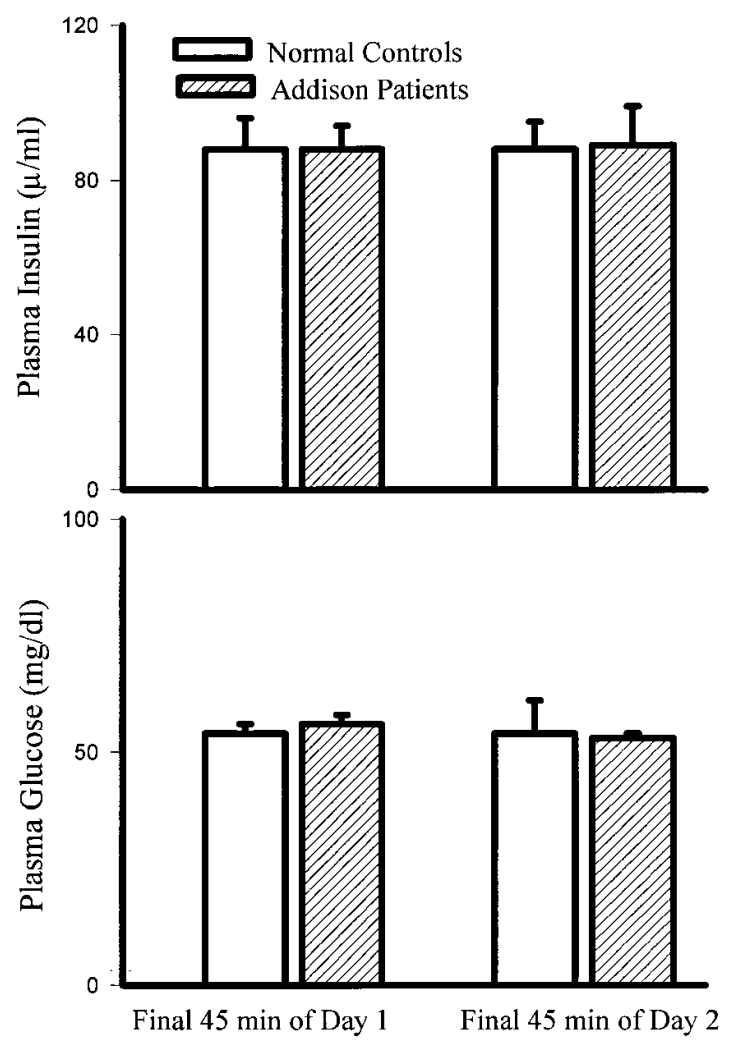

Figure 2. Effects of peripherally infused insulin (1.5 mU/kg per min) on arterialized plasma insulin and glucose levels in overnight fasted normal controls and patients with primary adrenocortical failure ( $A d$ dison Patients).

blunted by day 1 hypoglycemia ( $28 \pm 4$ vs. $46 \pm 7, P<0.01)$. However, in patients, day 1 hypoglycemia had no effect on reducing day 2 growth hormone levels ( $19 \pm 5 \mathrm{vs} .18 \pm 5 \mathrm{pg} / \mathrm{ml})$. Day 2 pancreatic polypeptide values (Fig. 5) in controls were blunted by day 1 hypoglycemia ( $830 \pm 121$ vs. $1,256 \pm 181 \mathrm{pg} / \mathrm{ml}$, $P<0.01)$, but were unaffected in the patient group $(1,245 \pm$ 267 vs. 1,229 $\pm 216 \mathrm{pg} / \mathrm{ml}$ ). Similarly, day 2 ACTH levels (Fig. 5 ) were blunted by day 1 hypoglycemia in controls ( $28 \pm 6$ vs. $94 \pm 26, P<0.01)$, but were unaffected in the patient group $(1,336 \pm 529$ vs. $1,253 \pm 478 \mathrm{pg} / \mathrm{ml})$.

\section{Direct muscle sympathetic nerve activity}

Due to large intersubject variation, muscle sympathetic nerve activity will be reported as incremental increases from baseline (Fig. 6). Day 2 MSNA responses in control experiments were significantly suppressed by day 1 hypoglycemia ( $+5 \pm 2$ vs. $+10 \pm 2$ bursts/min, $P<0.01)$. However, similar to neuroendocrine results, day 2 MSNA responses in the patient group were unaffected by day 1 hypoglycemia $(+10 \pm 2$ vs. $+7 \pm 2$ bursts/ $\min )$.

\section{Glucose flux}

Glucose-specific activity (disintegrations per minute per milligram) was in a similar steady state (Table III) during the control period of each experimental group (normal controls, $\mathrm{CV}=$ $3.5 \%$; patients, $\mathrm{CV}=2.9 \%$ ). By the final $45 \mathrm{~min}$ of day 2 hypoglycemic clamp studies, an isotopic steady state existed with 


\begin{tabular}{|c|c|c|c|c|c|c|c|c|}
\hline & & $\begin{array}{l}\text { Control } \\
\text { period }\end{array}$ & 30 & 60 & 75 & 90 & 115 & $120(\min )$ \\
\hline \multicolumn{9}{|l|}{ Epinephrine $(\mathrm{pg} / \mathrm{ml})$} \\
\hline \multirow[t]{2}{*}{ Normal controls } & Day 1 & $46 \pm 8$ & $120 \pm 31$ & $648 \pm 85$ & $778 \pm 95$ & $809 \pm 112$ & $794 \pm 113$ & $760 \pm 95$ \\
\hline & Day 2 & $55 \pm 9$ & $55 \pm 9$ & $305 \pm 59 *$ & $411 \pm 60^{*}$ & $434 \pm 64 *$ & $346 \pm 46^{*}$ & $423 \pm 59 *$ \\
\hline \multirow{2}{*}{$\begin{array}{l}\text { Primary adrenocortical } \\
\text { failure patients }\end{array}$} & Day 1 & $39 \pm 3$ & $39 \pm 3$ & $109 \pm 34$ & $143 \pm 27$ & $165 \pm 29$ & $167 \pm 31$ & $150 \pm 24$ \\
\hline & Day 2 & $45 \pm 7$ & $45 \pm 7$ & $87 \pm 18$ & $114 \pm 26$ & $129 \pm 25$ & $138 \pm 27$ & $155 \pm 29$ \\
\hline \multicolumn{9}{|l|}{ Norepinephrine (pg/ml) } \\
\hline \multirow[t]{2}{*}{ Normal controls } & Day 1 & $162 \pm 8$ & $210 \pm 14$ & $294 \pm 17$ & $315 \pm 15$ & $331 \pm 26$ & $314 \pm 19$ & $302 \pm 20$ \\
\hline & Day 2 & $194 \pm 14$ & $204 \pm 10$ & $272 \pm 14^{\ddagger}$ & $287 \pm 15^{\ddagger}$ & $287 \pm 15^{\ddagger}$ & $288 \pm 15^{\ddagger}$ & $304 \pm 18^{\ddagger}$ \\
\hline \multirow{2}{*}{$\begin{array}{l}\text { Primary adrenocortical } \\
\text { failure patients }\end{array}$} & Day 1 & $260 \pm 40$ & $302 \pm 47$ & $426 \pm 47$ & $493 \pm 54$ & $539 \pm 47$ & $553 \pm 62$ & $586 \pm 93$ \\
\hline & Day 2 & $282 \pm 47$ & $343 \pm 58$ & $440 \pm 58$ & $516 \pm 54$ & $592 \pm 77$ & $628 \pm 94$ & $593 \pm 90$ \\
\hline \multicolumn{9}{|l|}{ Glucagon $(\mathrm{pg} / \mathrm{ml})$} \\
\hline \multirow[t]{2}{*}{ Normal controls } & Day 1 & $72 \pm 10$ & $96 \pm 11$ & $182 \pm 34$ & $204 \pm 30$ & $202 \pm 33$ & $196 \pm 32$ & $199 \pm 31$ \\
\hline & Day 2 & $64 \pm 7$ & $77 \pm 6$ & $116 \pm 14 *$ & $135 \pm 17 *$ & $139 \pm 16^{*}$ & $140 \pm 18 *$ & $144 \pm 20 *$ \\
\hline \multirow{2}{*}{$\begin{array}{l}\text { Primary adrenocortical } \\
\text { failure patients }\end{array}$} & Day 1 & $52 \pm 5$ & $67 \pm 7$ & $126 \pm 23$ & $124 \pm 25$ & $126 \pm 25$ & $130 \pm 29$ & $125 \pm 25$ \\
\hline & Day 2 & $52 \pm 7$ & $60 \pm 8$ & $92 \pm 13$ & $114 \pm 21$ & $118 \pm 20$ & $120 \pm 26$ & $126 \pm 23$ \\
\hline \multicolumn{9}{|l|}{ Growth hormone (ng/ml) } \\
\hline \multirow[t]{2}{*}{ Normal controls } & Day 1 & $2 \pm 1$ & $7 \pm 3$ & $36 \pm 7$ & $46 \pm 8$ & $46 \pm 7$ & $47 \pm 7$ & $45 \pm 7$ \\
\hline & Day 2 & $2 \pm 1$ & $3 \pm 1$ & $14 \pm 3^{*}$ & $25 \pm 4^{*}$ & $30 \pm 3 *$ & $30 \pm 4 *$ & $28 \pm 4 *$ \\
\hline \multirow{2}{*}{$\begin{array}{l}\text { Primary adrenocortical } \\
\text { failure patients }\end{array}$} & Day 1 & $3 \pm 1$ & $10 \pm 6$ & $21 \pm 8$ & $21 \pm 6$ & $19 \pm 5$ & $20 \pm 6$ & $17 \pm 5$ \\
\hline & Day 2 & $2 \pm 1$ & $5 \pm 3$ & $19 \pm 8$ & $22 \pm 7$ & $18 \pm 5$ & $18 \pm 5$ & $16 \pm 5$ \\
\hline \multicolumn{9}{|c|}{ Pancreatic polypeptide (pg/ml) } \\
\hline \multirow[t]{2}{*}{ Normal controls } & Day 1 & $118 \pm 21$ & $190 \pm 100$ & $1542 \pm 241$ & $1486 \pm 220$ & $1325 \pm 203$ & $1160 \pm 148$ & $1052 \pm 154$ \\
\hline & Day 2 & $125 \pm 19$ & $103 \pm 17$ & $593 \pm 120 *$ & $771 \pm 132 *$ & $954 \pm 136^{*}$ & $816 \pm 109^{*}$ & $780 \pm 104 *$ \\
\hline \multirow{2}{*}{$\begin{array}{l}\text { Primary adrenocortical } \\
\text { failure patients }\end{array}$} & Day 1 & $140 \pm 21$ & $196 \pm 104$ & $1436 \pm 212$ & $1472 \pm 296$ & $1289 \pm 292$ & $1134 \pm 256$ & $1086 \pm 222$ \\
\hline & Day 2 & $133 \pm 15$ & $187 \pm 70$ & $861 \pm 202$ & $1217 \pm 231$ & $1315 \pm 255$ & $1196 \pm 197$ & $1187 \pm 194$ \\
\hline
\end{tabular}

Values are mean \pm SEM. * Day 2 values are significantly reduced $(P<0.05)$ compared with day 1 concentrations. ${ }^{*}$ Incremental increases from baseline are significantly reduced $(P<0.05)$ compared with day 1 values.

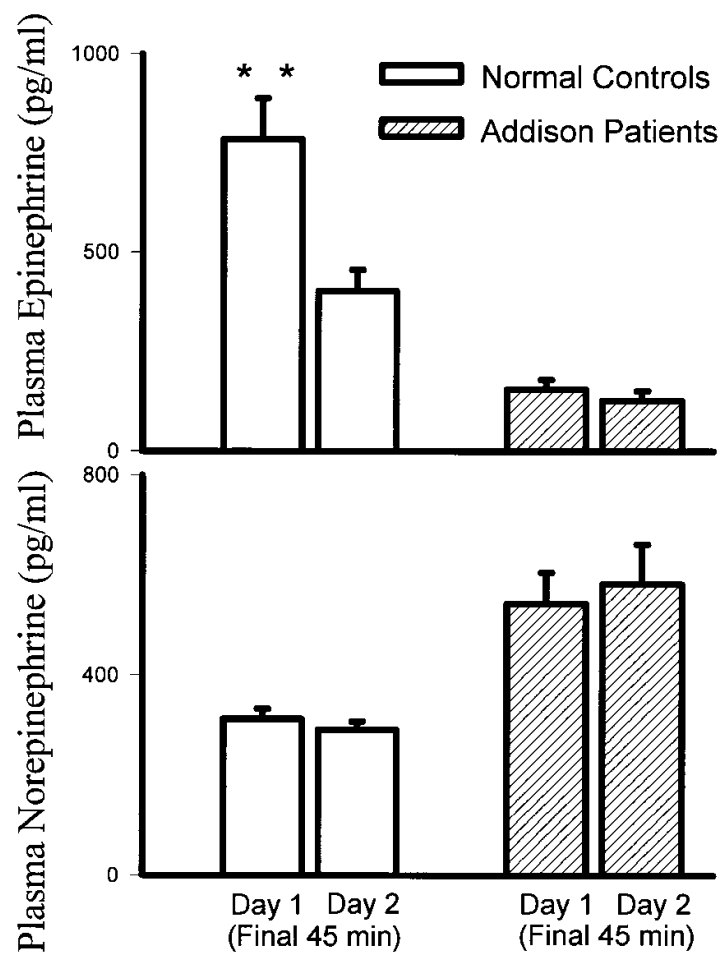

a CV of 3.2 and $3.7 \%$ for control and patient groups, respectively. Endogenous glucose production (Table III) was initially similar $(2.1 \pm 0.1 \mathrm{mg} / \mathrm{kg}$ per min $)$ in both groups. By the final 45 min of hypoglycemic clamp studies, endogenous glucose production was suppressed by a greater amount in controls compared with patient experiments $(1.0 \pm 0.2 \mathrm{vs} .1 .5 \pm 0.2 \mathrm{mg} / \mathrm{kg}$ per $\min ; P<0.05$ ). There was a trend for glucose use rates to be increased during the final 45 min of controls compared with patients $(2.4 \pm 0.2$ vs. $2.0 \pm 0.2 \mathrm{mg} / \mathrm{kg}$ per $\mathrm{min})$.

\section{Intermediary metabolism}

Day 1 hypoglycemia blunted day 2 lactate responses in normal controls ( $+966 \pm 72$ vs. $+510 \pm 68 \mathrm{M}, P<0.01$, respectively). Day 2 lactate levels in patients were unaffected by day 1 hypoglycemia (Table IV). In normal controls, day 1 hypoglycemia blunted day 2 glycerol levels $(45 \pm 5$ vs. $28 \pm 3 \mathrm{M}, P<0.01)$. Glycerol levels in the patient group were unaffected by day 1

Figure 3. Effects of peripherally infused insulin (1.5 mU/kg per min) and hypoglycemia on arterialized plasma epinephrine and norepinephrine levels in overnight fasted normal controls and patients with primary adrenocortical failure (Addison Patients). Day 2 plasma epinephrine values in normal controls are significantly reduced $(P<$ 0.01) compared with day 1 values. 


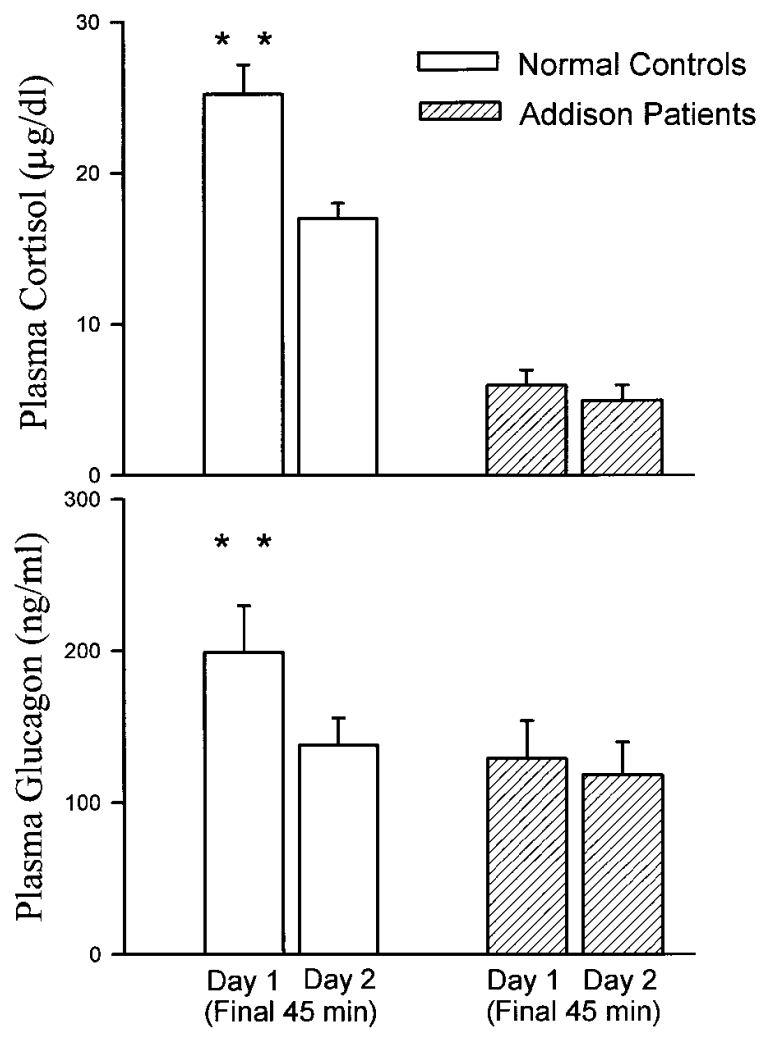

Figure 4. Effects of peripherally infused insulin ( $1.5 \mathrm{mU} / \mathrm{kg}$ per $\mathrm{min})$ and hypoglycemia $(53 \pm 1 \mathrm{mg} / \mathrm{dl})$ on arterialized plasma glucagon and cortisol in overnight fasted normal controls and patients with primary adrenocortical failure (Addison Patients). Day 2 plasma cortisol and glucagon levels in normal controls are significantly reduced $(P<$ $0.01)$ compared with day 1 values.

hypoglycemia ( $48 \pm 7$ vs. $44 \pm 7 \mathrm{M}, P<0.01$ ). Similarly, in normal controls, day 1 blunted day 2 NEFA levels $(260 \pm 32$ vs. $180 \pm 15 \mathrm{M}, P<0.05)$. However, in patients, day 1 hypoglycemia had no effect on day 2 NEFA levels $(253 \pm 39$ vs. $296 \pm 51 \mathrm{M})$. Day 2 blood alanine and 3-hydroxybutyrate levels responded similarly after day 1 hypoglycemia in control and patient groups (Table IV).

\section{Hypoglycemic symptoms}

Day 1 hypoglycemia significantly blunted day 2 hypoglycemic symptom response scores in normal controls $(n=7),(+16 \pm 5$ vs. $+3 \pm 2, P<0.01)$. This blunted symptom response was caused by an almost exclusive reduction in autonomic symptoms. Day 1 hypoglycemia in patients resulted in no blunting of day 2 symptom responses $(+14 \pm 3$ vs. $+15 \pm 3)$.

\section{Cardiovascular parameters}

Day 1. Systolic blood pressure (112 \pm 4 to $121 \pm 5 \mathrm{mmHg}$ ) and heart rate $(62 \pm 2$ to $70 \pm 3$ beats $/ \mathrm{min})$ in controls increased during day 1 morning hypoglycemia studies. In patients, systolic blood pressure (115 \pm 6 to $113 \pm 7 \mathrm{mmHg}$ ) and heart rate $(72 \pm 5$ to $67 \pm 6$ beats $/ \mathrm{min})$ remained similar to baseline. Diastolic blood pressure fell similarly in controls ( $62 \pm 2$ to $56 \pm 2 \mathrm{mmHg}$ ) and patients $(71 \pm 3$ to $65 \pm 3 \mathrm{mmHg}$ ).

Day 2. Similar to day 1 results, systolic blood pressure (114 \pm 3 to $122 \pm 5 \mathrm{mmHg}$ ) and heart rate $(64 \pm 3$ to $73 \pm 3$ beats/ min) increased in controls, but did not increase from baseline

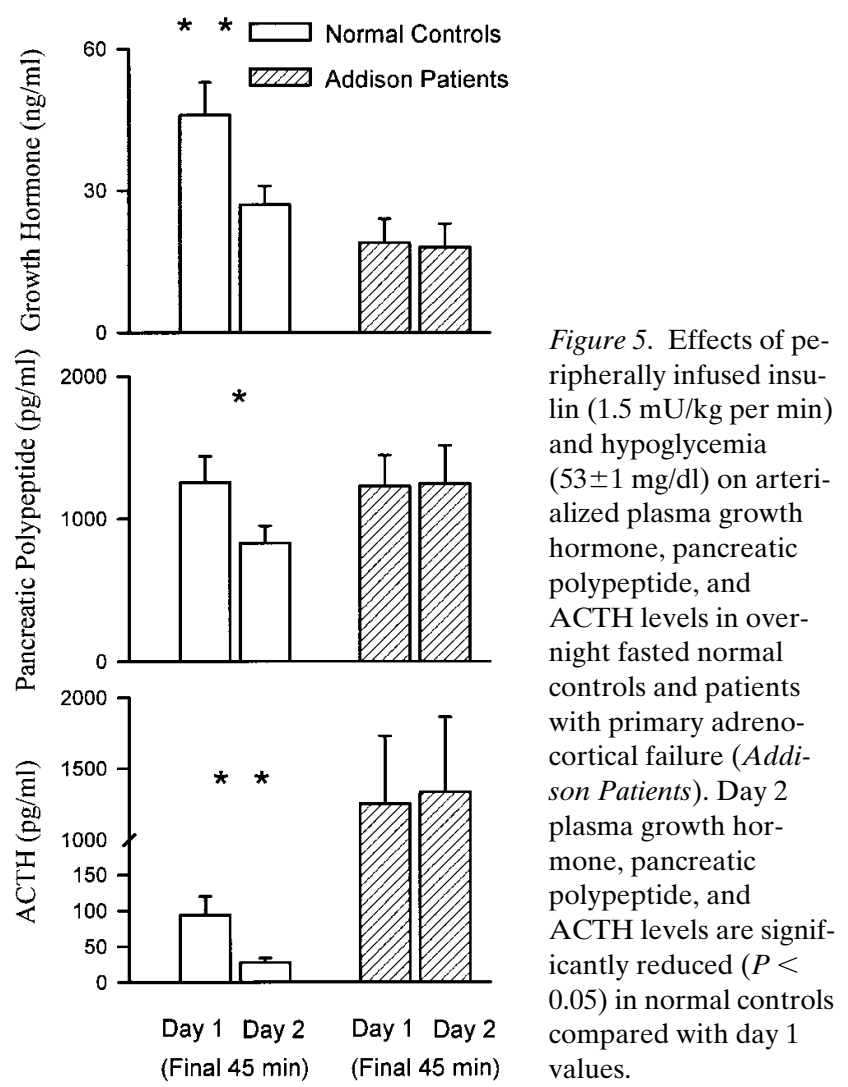

in patients (systolic blood pressure $112 \pm 8$ to $121 \pm 9 \mathrm{mmHg}$, heart rate $78 \pm 6$ to $74 \pm 6$ beats $/ \mathrm{min}$ ). Diastolic blood pressure fell during control experiments ( $63 \pm 2$ to $56 \pm 2 \mathrm{mmHg}$ ), but remained unchanged in patients $(69 \pm 3$ to $69 \pm 4 \mathrm{mmHg})$.

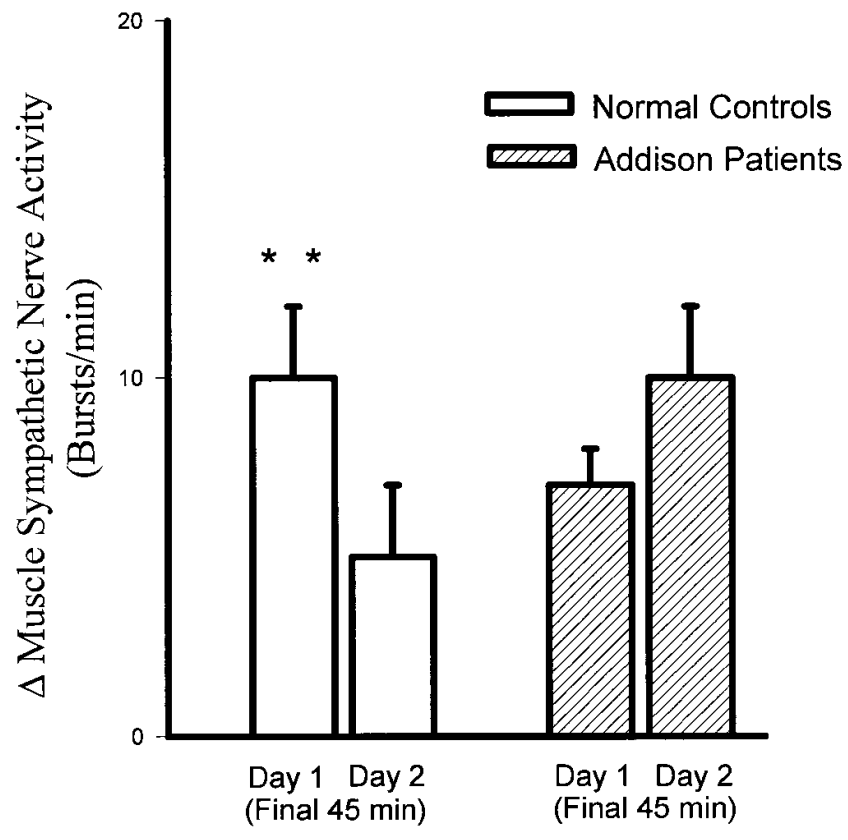

Figure 6. Effects of peripherally infused insulin $(1.5 \mathrm{mg} / \mathrm{kg}$ per $\mathrm{min})$ and hypoglycemia $(53 \pm 1 \mathrm{mg} / \mathrm{dl})$ on incremental increase from baseline MSNA in overnight fasted normal controls and patients with primary adrenocortical failure (Addison Patients). Day 2 MSNA was significantly reduced $(P<0.01)$ in normal controls compared with day 1 values. 
Table III. Effects of Antecedent (Day 1) Hyperinsulinemic Hypoglycemia on Glucose Kinetics During Day 2 Hypoglycemia $(53 \pm 2 \mathrm{mg} / \mathrm{dl})$

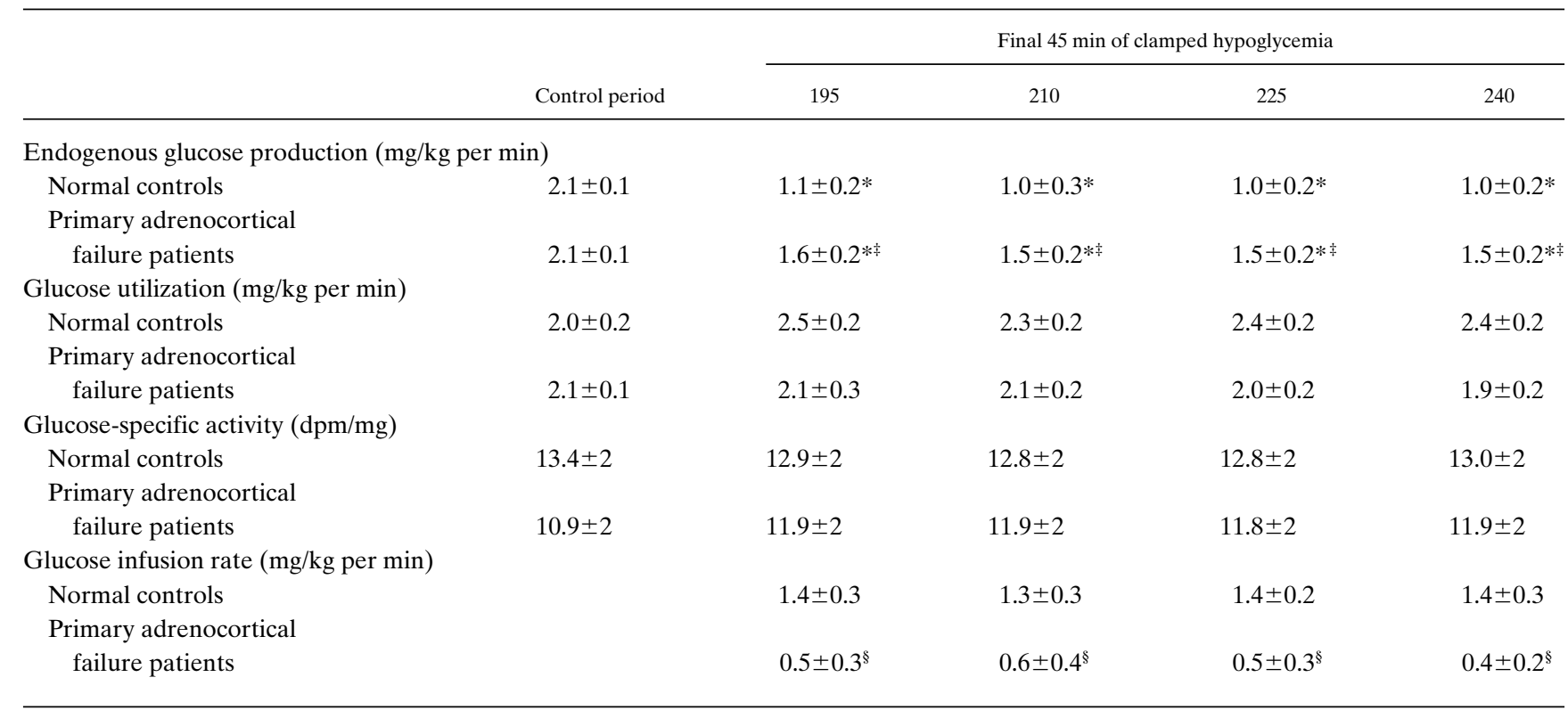

Values are mean \pm SEM. *Final 45 -min values are significantly suppressed $(P<0.05)$ compared with control period. ${ }^{*}$ Final 45 -min values are significantly increased $(P<0.05)$ compared with normal controls. ${ }^{8}$ Final 45 -min values are significantly reduced $(P<0.05)$ compared with normal controls.

\section{Discussion}

The purpose of this study was to determine whether prevention of an increase in plasma cortisol levels during antecedent hypoglycemia preserves subsequent autonomic counterregulatory responses. The present results demonstrate that two episodes of antecedent hypoglycemia $(53 \pm 1 \mathrm{mg} / \mathrm{dl})$ in patients with primary adrenocortical failure and fixed basal cortisol levels do not result in autonomic counterregulatory failure during subsequent hypoglycemia. This in marked contrast with the significant blunting of subsequent counterregulatory responses observed in a control group in which cortisol levels were allowed to rise during episodes of identical antecedent hypoglycemia.

We have recently reported in normal humans that increases of plasma cortisol simulating levels usually obtained during hypoglycemia produce similar blunting of autonomic nervous system counterregulatory responses to subsequent hypoglycemia (16). These previous data certainly suggest that increases in plasma cortisol may play a role in the pathogenesis of hypoglycemia-associated autonomic failure. However, two important questions remained unanswered after our previous study: (a) Will prevention of an increase in plasma cortisol during hypoglycemia preserve subsequent autonomic counterregulatory responses? and (b) Are there redundant mechanisms that can blunt subsequent counterregulation even if increases in plasma cortisol are abolished? To answer these questions, a group of patients with documented primary adrenocortical failure were studied to ensure that cortisol levels would not increase during day 1 hypoglycemia. $5 \mathrm{~d}$ before and during each 2-d study, the patients' usual oral glucocorticoid treatment (prednisolone or hydrocortisone) was replaced with a continuous subcutaneous infusion of cortisol programmed to produce a normal circadian rhythm. Thus, during the 2-d study, plasma cortisol levels were programmed to peak $(16 \pm 2 \mathrm{~g} / \mathrm{dl})$ at 0600 hours and decline to basal levels $(5$ $\mathrm{g} / \mathrm{dl}$ ) by midday. The patients usual mineralocorticoid therapy was maintained during both study days. This model of replacement therapy was very well tolerated, with each patient completing the study in a similar fashion compared with normal controls.

Antecedent hypoglycemia in controls had a profound effect on blunting subsequent counterregulatory responses. Day 2 neuroendocrine (glucagon, cortisol, growth hormone, ACTH) and ANS (epinephrine, norepinephrine, pancreatic polypeptide, MSNA) responses were all significantly reduced (30$70 \%$ ) after day 1 hypoglycemia. These results are supported by previous data in normal individuals $(5-7,9)$, which have also demonstrated that antecedent hypoglycemia can result in a spectrum of blunted neuroendocrine responses during subsequent hypoglycemia. However, in marked contrast with controls, prevention of an increase in plasma cortisol during day 1 hypoglycemia in the patient group preserved neuroendocrine, metabolic, and ANS counterregulatory responses during subsequent hypoglycemia.

These present data are therefore consistent with the hypothesis that hypoglycemia-induced increases in plasma cortisol are a major mechanism responsible for causing subsequent hypoglycemia-associated autonomic failure. Additionally, the preservation of day 2 counterregulatory responses argues against other redundant factors having a role in causing blunted counterregulatory responses after antecedent hypoglycemia. A third significant finding from these studies is the demonstration that patients with primary adrenocortical failure have altered neuroendocrine counterregulatory responses. This interesting finding merits further discussion, particularly in relation to the other significant findings of the study. In the patient group, day 2 epinephrine levels were un- 


\begin{tabular}{|c|c|c|c|c|c|c|}
\hline & & \multirow[b]{2}{*}{ Control period } & \multicolumn{4}{|c|}{ Final 45 min of clamped hypoglycemia } \\
\hline & & & 195 & 210 & 225 & 240 \\
\hline \multicolumn{7}{|l|}{ Blood lactate $(\mu \mathrm{M})$} \\
\hline \multirow[t]{2}{*}{ Normal controls } & Day 1 & $615 \pm 56$ & $1418 \pm 89$ & $1548 \pm 114$ & $1607 \pm 134$ & $1731 \pm 152$ \\
\hline & Day 2 & $906 \pm 81$ & $1371 \pm 74$ & $1420 \pm 63$ & $1398 \pm 63$ & $1457 \pm 82$ \\
\hline \multirow{2}{*}{$\begin{array}{l}\text { Primary adrenocortical } \\
\text { failure patients }\end{array}$} & Day 1 & $856 \pm 115$ & $1182 \pm 117$ & $1143 \pm 106$ & $1091 \pm 70$ & $1082 \pm 104$ \\
\hline & Day 2 & $954 \pm 118$ & $1125 \pm 60$ & $1072 \pm 65$ & $1016 \pm 73$ & $1032 \pm 89$ \\
\hline \multicolumn{7}{|l|}{ Blood alanine $(\mu \mathrm{M})$} \\
\hline \multirow[t]{2}{*}{ Normal controls } & Day 1 & $236 \pm 17$ & $239 \pm 15$ & $238 \pm 14$ & $236 \pm 13$ & $225 \pm 19$ \\
\hline & Day 2 & $388 \pm 25$ & $353 \pm 18$ & $342 \pm 17$ & $324 \pm 16$ & $328 \pm 20$ \\
\hline \multirow{2}{*}{$\begin{array}{l}\text { Primary adrenocortical } \\
\text { failure patients }\end{array}$} & Day 1 & $341 \pm 35$ & $315 \pm 30$ & $304 \pm 31$ & $285 \pm 29$ & $275 \pm 31$ \\
\hline & Day 2 & $414 \pm 38$ & $357 \pm 22$ & $351 \pm 25$ & $332 \pm 24$ & $317 \pm 23$ \\
\hline \multicolumn{7}{|l|}{ Blood glycerol $(\mu \mathrm{M})$} \\
\hline \multirow[t]{2}{*}{ Normal controls } & Day 1 & $48 \pm 5$ & $44 \pm 5$ & $45 \pm 5$ & $46 \pm 5$ & $46 \pm 4$ \\
\hline & Day 2 & $41 \pm 3$ & $24 \pm 3^{*}$ & $27 \pm 3^{*}$ & $29 \pm 3 *$ & $31 \pm 3 *$ \\
\hline \multirow{2}{*}{$\begin{array}{l}\text { Primary adrenocortical } \\
\text { failure patients }\end{array}$} & Day 1 & $64 \pm 7$ & $41 \pm 3$ & $47 \pm 5$ & $54 \pm 10$ & $53 \pm 7$ \\
\hline & Day 2 & $73 \pm 9$ & $39 \pm 5$ & $39 \pm 5$ & $48 \pm 8$ & $48 \pm 8$ \\
\hline \multicolumn{7}{|c|}{ Blood 3-hydroxybutyrate $(\mu \mathrm{M})$} \\
\hline \multirow[t]{2}{*}{ Normal controls } & Day 1 & $72 \pm 21$ & $12 \pm 4$ & $11 \pm 4$ & $13 \pm 4$ & $12 \pm 4$ \\
\hline & Day 2 & $35 \pm 12$ & $8 \pm 3$ & $8 \pm 3$ & $9 \pm 2$ & $7 \pm 2$ \\
\hline \multirow{2}{*}{$\begin{array}{l}\text { Primary adrenocortical } \\
\text { failure patients }\end{array}$} & Day 1 & $87 \pm 20$ & $13 \pm 2$ & $12 \pm 2$ & $14 \pm 3$ & $12 \pm 3$ \\
\hline & Day 2 & $48 \pm 8$ & $12 \pm 2$ & $12 \pm 2$ & $13 \pm 3$ & $15 \pm 3$ \\
\hline \multicolumn{7}{|l|}{ Plasma NEFA $(\mu \mathrm{M})$} \\
\hline \multirow[t]{2}{*}{ Normal controls } & Day 1 & $637 \pm 63$ & $278 \pm 29$ & $256 \pm 32$ & $248 \pm 35$ & $255 \pm 33$ \\
\hline & Day 2 & $520 \pm 42$ & $191 \pm 18^{*}$ & $181 \pm 18^{*}$ & $171 \pm 15^{*}$ & $180 \pm 14^{*}$ \\
\hline \multirow{2}{*}{$\begin{array}{l}\text { Primary adrenocortical } \\
\text { failure patients }\end{array}$} & Day 1 & $670 \pm 74$ & $250 \pm 42$ & $246 \pm 39$ & $250 \pm 41$ & $261 \pm 36$ \\
\hline & Day 2 & $695 \pm 69$ & $297 \pm 50$ & $289 \pm 47$ & $293 \pm 53$ & $316 \pm 48$ \\
\hline
\end{tabular}

Values are mean \pm SEM. * Day 2 final 45 -min values are significantly decreased compared with day 1 values.

affected by day 1 hypoglycemia. Epinephrine levels in patients, however, were markedly reduced compared with controls. These low levels raise the question whether day 2 epinephrine values in patients appeared unaffected by day 1 hypoglycemia due to the fact that they were already maximally suppressed and therefore incapable of further blunting. We believe this is not the situation, as epinephrine levels exhibited similar approximately fourfold increases during both days of hypoglycemia, thereby indicating equivalent adrenal reserve and easily measurable increases in epinephrine values. However, we do stress that the already reduced epinephrine responses in patients limit any conclusion that day 2 adrenomedullary responses to hypoglycemia were unaffected by antecedent hypoglycemia. The finding of reduced epinephrine levels in the patient group is most likely explained by reduced adrenal phenylethanolamine- $N$-methyltransferase (PNMT) activity. Over 30 yr ago, Wurtman and Axelrod demonstrated that glucocorticoids have an important role in regulation of epinephrine synthesis in the adrenal medulla (33). In a series of classic experiments, these authors demonstrated that high levels of glucocorticoids are needed to maintain normal adrenal PNMT activity, which is the enzyme responsible for catalyzing the final step of catecholamine biosynthesis (norepinephrine $\rightarrow$ epinephrine). Very high levels of cortisol are required in adrenal glands for normal PNMT function. Due to the portal system of adrenal blood flow from cortex to medulla, levels of cortisol in the medulla may be $\sim 100$-fold higher compared with periph- eral circulation concentrations. Thus, although in this study we recreated a normal circadian rhythm of cortisol in the peripheral circulation, we could not create the very high levels of cortisol usually occurring in adrenal glands. The finding, therefore, of blunted epinephrine in the patient group is plausibly explained by reduced adrenal PNMT activity in these individuals. Supporting this view are three previous studies in ACTHand cortisol-deficient children that have reported blunted epinephrine responses (reduced by $70-90 \%$ ) to hypoglycemia and exercise (34-36).

It is therefore pertinent to assess other markers of ANS activity in the patient group to determine if day 1 hypoglycemia had any effects on subsequent counterregulatory responses. Incremental increases of norepinephrine were blunted $(\sim 33 \%)$ during day 2 hypoglycemia in controls. In the patient group, norepinephrine levels were $(a)$ increased twofold compared with controls, and $(b)$ day 2 values were clearly unaffected by day 1 hypoglycemia. Norepinephrine levels in patients, therefore, provided a larger signal compared with controls and demonstrate that plasma catecholamine counterregulatory responses can be preserved in the absence of antecedent increases in cortisol. The mechanism of elevated norepinephrine levels in the patient group is also most likely explained by reduced adrenal PNMT levels. The strongest evidence for preservation of ANS counterregulatory responses in patients are the microneurography data. Incremental increases in MSNA, a direct measurement of sympathetic nerve activity, 
were significantly blunted in controls during day 2 hypoglycemia. On the other hand, in patients, day 1 incremental increases in MSNA were similar to controls and day 2 values were clearly unaffected by day 1 hypoglycemia. Hypoglycemic symptom data complements the above three parameters of sympathetic nervous system activity. Day 1 autonomic symptom scores were equivalent in control and patient groups. Similar to and consistent with catecholamine and MSNA data, autonomic symptoms were significantly blunted in controls during day 2 hypoglycemia. However, unlike controls, day 2 autonomic symptoms in patients were unaffected by day 1 hypoglycemia. Day 1 pancreatic polypeptide responses (a marker of vagal parasympathetic afferent innervation to the pancreas) were equivalent in control and patient groups. Similar to other markers of ANS activity, day 2 pancreatic polypeptide levels were significantly blunted after antecedent hypoglycemia in controls, but were unaffected by day 1 hypoglycemia in patients. Thus, from the above, it is clear that sympathetic nervous system counterregulatory responses and a marker of parasympathetic counterregulatory activity were preserved after antecedent hypoglycemia, when an increase in cortisol was prevented.

Day 2 glucagon, growth hormone, and ACTH levels in controls were significantly blunted after antecedent hypoglycemia. Contrary to this finding, in the patient group, day 2 glucagon, growth hormone, and ACTH levels were unaffected by day 1 hypoglycemia. These findings are again consistent with the hypothesis that increased cortisol is a major mechanism responsible for antecedent hypoglycemia, causing subsequent counterregulatory failure. It should be noted that day 1 glucagon, growth hormone, and ACTH levels were not similar in control and patient groups. Glucagon and growth hormone levels were reduced by $\sim 33$ and $66 \%$, respectively, in patients, whereas ACTH values were increased $\sim 13$-fold compared with controls. It may also be argued that, similar to the epinephrine data, day 1 glucagon responses in patients were severely reduced and incapable of further blunting. We believe this to be unlikely as there were similar, easily measurable, increases in glucagon during both days of hypoglycemia. However, we must stress that the already reduced glucagon responses in patients limit the conclusion that day 1 glucagon responses were unaffected by subsequent hypoglycemia. The mechanisms responsible for altered neuroendocrine counterregulatory responses in the patient group are not fully understood and deserve further investigation. However, the ACTH data in the patients provide another interesting piece of information. Despite dramatically high day 1 levels of ACTH, day 2 counterregulatory responses were unaffected. This finding strongly argues against increases in ACTH having a significant role in causing subsequent blunted counterregulation. This is significant as it isolated increases in cortisol rather than alterations of the entire hypothalamic-pituitary-adrenal axis as a cause of subsequent counterregulatory failure.

Metabolic counterregulation was also better preserved when increases of day 1 cortisol were prevented. Endogenous glucose production was suppressed $50 \%$ in controls, but only $25 \%$ in patients. It is interesting to speculate why EGP was increased in the patient group relative to controls despite higher levels of epinephrine in the latter group. Although plasma norepinephrine and ACTH levels were considerably elevated in patients, it is unlikely that either or both of these hormones could have directly increased EGP (37). A more likely possi- bility is that elevated levels of norepinephrine and ACTH indirectly resulted in increased EGP in patients via the hormones' lipolytic effects $(38,39)$. Recent studies have demonstrated that lipolysis can exert significant quantitative effects on EGP $(40,41)$. Increased NEFA levels provide energy for gluconeogenesis, and glycerol is an important substrate for this process during hypoglycemia (42). Day 2 lipolytic activity in patients was clearly increased relative to controls. By the final $30 \mathrm{~min}$ of day 2 studies, plasma NEFA levels were approximately twofold higher and blood glycerol values were $\sim 50 \%$ increased in patients compared with controls.

In summary, these results demonstrate that prior hypoglycemia in healthy controls resulted in significant blunting of subsequent neuroendocrine, ANS, and metabolic counterregulatory responses. In marked contrast, preventing increases in plasma cortisol during antecedent hypoglycemia in patients with primary adrenocortical failure preserved the majority of ANS (norepinephrine, MSNA, pancreatic polypeptide, autonomic symptoms, neuroendocrine [growth hormone and ACTH]), and metabolic (EGP and lipolysis) counterregulatory responses. Epinephrine and glucagon may also have been unaffected by day 1 hypoglycemia in patients. However, the fact that the responses of these two hormones to hypoglycemia were already reduced in the patients limits the ability to determine convincingly whether the absence of cortisol prevented further blunting. We conclude that $(a)$ prevention of increases of cortisol during antecedent hypoglycemia preserves many critical ANS counterregulatory responses to subsequent hypoglycemia, $(b)$ hypoglycemia-induced increases in plasma cortisol levels are a major mechanism responsible for causing subsequent hypoglycemic counterregulatory failure, and $(c)$ our results suggest that other mechanisms (apart from cortisol) do not play a major role in causing hypoglycemia-associated autonomic failure.

\section{Acknowledgments}

We thank Eric Allen and Pam Venson for technical assistance. We are grateful to Bill Pugh for kindly measuring the pancreatic polypeptide levels reported in this manuscript. We also greatly appreciate the skilled nursing support and care provided by the staff of the Vanderbilt General Clinical Research Center.

This work was supported by a grant from the Juvenile Diabetes Foundation International, National Institutes of Health grant RO1 DK-45369, a Diabetes Research and Training Center grant (5P60AM20593-08), and a Clinical Research Center grant (MO1-RR00095).

\section{References}

1. The Diabetes Control and Complications Trial Research Group. 1993. The effect of intensive treatment of diabetes on the development and progression of long term complications in insulin-dependent diabetes mellitus. N. Engl. J. Med. 329:977-986.

2. Amiel, P., R. Sherwin, D. Simonson, and W. Tamborlane. 1988. Effect of intensive insulin therapy on glycemic thresholds for counterregulatory hormone release. Diabetes. 37:901-907.

3. Simonson, D., W. Tamborlane, R. Defronzo, and R. Sherwin. 1985. Intensive insulin therapy reduces the counterregulatory hormone responses to hypoglycemia in patients with type I diabetes. Ann. Intern. Med. 103:184-190.

4. Powell, A., R. Sherwin, and G. Shulman. 1993. Impaired hormonal responses to hypoglycemia in spontaneously diabetic and recurrently hypoglycemic rats. J. Clin. Invest. 92:2667-2674.

5. Heller, S., and P. Cryer. 1991. Reduced neuroendocrine and symptomatic responses to subsequent hypoglycemia after 1 episode of hypoglycemia in nondiabetic humans. Diabetes. 40:223-226.

6. Widom, B., and D. Simonson. 1992. Intermittent hypoglycemia impairs glucose counterregulation. Diabetes. 41:1597-1602.

7. Davis, M., and H. Shamoon. 1991. Counterregulatory adaption to recur- 
rent hypoglycemia in normal humans. J. Clin. Endocrinol. Metab. 73:995-1001.

8. Dagogo-Jack, S., S. Craft, and P. Cryer. 1993. Hypoglycemia-associated autonomic failure in IDDM. J. Clin. Invest. 91:819-828.

9. Veneman, T., A. Mitrakou, M. Mokan, P. Cryer, and J. Gerich. 1993. Induction of hypoglycemic unawareness by asymptomatic nocturnal hypoglycemia. Diabetes. 42:1233-1237.

10. Davis, M., M. Mellman, and H. Shamoon. 1992. Further defects in counterregulatory responses induced by recurrent hypoglycemia in IDDM. Diabetes. 41:1335-1340.

11. Mitrakou, A., C. Fanelli, T. Veneman, G. Perriello, S. Raptis, P. Brunetti, P. Cryer, J. Gerich, and G. Bolli. 1993. Reversibility of unawareness of hypoglycemia in patients with insulinomas. N. Engl. J. Med. 329:834-839.

12. Davis, M., and H. Shamoon. 1991. Deficient counterregulatory hormone responses during hypoglycemia in a patient with insulinoma. J. Clin. Endocrinol. Metab. 72:788-792.

13. Maran, A., J. Taylor, I. Macdonald, and S. Amiel. 1992. Evidence for reversibility of defective counterregulation in a patient with insulinoma. Diabet. Med. 9:765-768.

14. Cryer, P. 1992. Iatrogenic hypoglycemia as a cause of hypoglycemiaassociated autonomic failure in IDDM. Diabetes. 41:255-260.

15. Boyle, P.J., R.L. Nagy, A.M. O'Connor, S.F. Kempers, R.A. Yeo, and C. Qualls. 1994. Adaptation in brain glucose uptake following recurrent hypoglycemia. Proc. Natl. Acad. Sci. USA. 91:9352-9356.

16. Davis, S.N., C. Shavers, F. Costa, and R. Mosqueda-Garcia. 1996. Role of cortisol in the pathogenesis of deficient counterregulation after antecedent hypoglycemia in normal humans. J. Clin Invest. 98:680-691.

17. Abumrad, N., D. Rabin, M. Diamond, and W. Lacy. 1981. Use of a healed superficial hard vein as an alternative site for measurement of amino acid concentration and for the study of glucose and alanine kinetics in man. $M e$ tabolism. 30:936-940.

18. Sherwin, R.S., K. Kramer, J. Robin, and R. Andres. 1978. A model of the kinetics of insulin in man. J. Clin. Invest. 53:1481-1492.

19. Defronzo, R., K. Tobin, and R. Andres. 1979. Glucose clamp technique: a method for quantifying insulin secretion and resistance. Am. J. Physiol. 237: E216-E223.

20. Wall, J., R. Steele, C. Debodo, and N. Altszuler. 1957. Effect of insulin on utilization and production of circulating glucose. Am. J. Physiol. 189:43-50.

21. Wallin, B., G. Sundiot, B. Eriksson, P. Domniak, H. Grobecker, and L. Lindblad. 1981. Plasma noradrenaline correlates to sympathetic muscle nerve activity in normotensive man. Acta Physiol. Scand. 111:69-73.

22. Fagius, J., F. Niklasson, and C. Berne. 1986. Sympathetic outflow in human muscle nerves increases during hypoglycemia. Diabetes. 35:1124.

23. Fagius, J., and C. Berne. 1989. Changes of sympathetic nerve activity induced by 2-deoxy-D-glucose infusion in humans. Am. J. Physiol. 256:E714E720.

24. Anderson, E., P. Hoffman, T. Balon, C. Sinkey, and A. Mark. 1992. Hyperinsulinemia produces both sympathetic neural activation and vasodilatation in normal humans. J. Clin. Invest. 87:2246-2252.

25. Cherrington, A.D., W. Lacy, and J.L. Chiasson. 1978. Effect of glucagon on glucose production during insulin deficiency in the dog. J. Clin. Invest. 62: 664-667.
26. Morgan, C., and A. Lazarow. 1963. Immunoassay of insulin: two antibody system plasma levels in normal, subdiabetic and diabetic rats. Diabetes. $12: 115$.

27. Causon, R., M. Carruthers, and R. Rodnight. 1981. Assay of plasma catecholamines by liquid chromatography with electrochemical detection. Anal. Biochem. 116:223-226.

28. Hunter, W., and F. Greenwood. 1962. Preparation of iodine 131 labeled human growth hormone of high specific activity. Nature (Lond.). 194:495-496.

29. Hagopian, W., E. Lever, D. Cen, D. Emmonoud, K. Polonsky, W. Pugh, A. Moosa, and J. Jaspan. 1983. Predominance of renal and absence of hepatic metabolism of pancreatic polypeptide in the dog. Am. J. Physiol. 245:171-177.

30. Nicholson, W., D. Davis, B. Sherrell, and D. Orth. 1984. Rapid radioimmunoassay for corticotropin in unextracted human plasma. Clin. Chem. 30: 259-265.

31. Lloyd, B., J. Burrin, P. Symthe, and K.G.M.M. Alberti. 1978. Enzymatic fluorometric continuous flow assays for blood glucose, lactate, pyruvate, alanine, glycerol and 3-hydroxybutyrate. Clin. Chem. 24:1724-1729.

32. Cox, D., P. Cryer, L. Gonder-Frederick, W. Clarke, and B. Antoun. 1993. Perceived symptoms in the recognition of hypoglycemia. Diabetes Care. 16:519-527.

33. Wurtman, R.J., and J. Axelrod. 1966. Control of enzymatic synthesis of adrenaline in the adrenal medulla by adrenal cortical steroids. J. Biol. Chem. 241:2301-2305.

34. Aynsley-Green, A., M. Moncrieft, S. Ratter, C. Benedict, C. Storrs, and R.H. Wilkinson. 1978. Isolated ACTH deficiency. Arch. Dis. Child. 53:499-502.

35. Hung, W., and C.J. Migeon. 1968. Hypoglycemia in a two year old boy with adrenocorticotropic hormone $(\mathrm{ACTH})$ deficiency (probably isolated) and adrenal medullary unresponsiveness to insulin induced hypoglycemia. J. Clin. Endocrinol. 28:146-152

36. Rudman, D., S. Moffitt, P. Fernhoff, D. Blackston, and B. Faraj. 1981. Epinephrine deficiency in hypocorticotropic hypopituitary children. J. Clin. Endocrinol. Metab. 53:722-729.

37. Connolly, C., K. Steiner, R. Stevenson, D. Neal, P. Williams, K. Alberti, and A.D. Cherrington. 1991. Regulation of glucose metabolism by norepinephrine in conscious dogs. Am. J. Physiol. 261:E764-E772.

38. Connolly, C., K. Steiner, R. Stevenson, D. Neal, P. Williams, K. Alberti, and A.D. Cherrington. 1991. Regulation of lipolysis and ketogenesis by norepinephrine in conscious dogs. Am. J. Physiol. 261:E466-E472.

39. Schwandt, P., and W. Richter. 1982. Effects of pituitary peptides on fat metabolism. Int. J. Obes. 6:49-54.

40. Prager, R., P. Wallace, and J.M. Olefsky. 1987. Direct and indirect effects of insulin to inhibit hepatic glucose output in obese subjects. Diabetes. 36: 607-611.

41. Rebrin, K., G.M. Steil, L. Getty, and R.N. Bergman. 1995. Free fatty acid as a link in the regulation of hepatic glucose output by peripheral insulin. Diabetes. 44:1038-1045.

42. Davis, S.N., R. Dobbins, C. Tarumi, J. Jacobs, D. Neal, and A.D. Cherrington. 1995. Paradoxical insulin-induced increase in gluconeogenesis in response to prolonged hypoglycemia in conscious dogs. Am. J. Physiol. 268:E521E530. 